Salvador GALLARDO CABRERA, Sobre la tierra no hay medida, México: Libros del Umbral 2008, 167 pp.

Lo ficticio no se encuentra jamás en las cosas ni en los hombres, sino en la imposible verosimilitud de aquello que está entre ambos: encuentros, proximidad de lo más lejano, ocultación absoluta del lugar donde nos encontramos.

Michel Foucault

\title{
El espacio de la filosofía
}

Varias veces me he preguntado por la naturaleza de la filosofía. Esa pregunta, que muchos nos hacemos y que pocos han contestado dignamente, volvió a preocuparme recientemente con el motivo de una lectura, de ésas de carácter filosófico, que más que ofrecernos múltiples respuestas, nos dejan con un puñado considerable de preguntas, buenas preguntas. El libro al que hago alusión lleva por título Sobre la tierra no hay medida y su autor, oriundo de Aguascalientes, es Salvador Gallardo Cabrera.

Este libro, breve en extensión pero extenso en contenido, aborda varios tópicos desde una temática principal. Me parece que la aportación principal que el autor nos ofrece es, cosa seria, un nuevo espacio para la filosofía: una filosofía del espacio; un recorrido, si no una navegación, por los lugares de la representación espacial.

El entramado que da lugar al texto sigue tres parajes principales: zarpa del régimen de las islas, avanza por una tira de migraciones por los desiertos de mar y hielo, y se aventura finalmente - para perderse de vista, puesto que no busca un puerto seguro dónde echar sus anclas - en las máximas políticas del mar.

El espacio que recorre el texto es el inaugurado por dos figuras predominantes de la filosofía contemporánea: Gilles Deleuze y Michel Foucault. Sin embargo sus senderos son diversos y por ellos 
transitan filósofos, poetas, artistas, matemáticos y geómetras, metafísicos, historiadores, teólogos, tlatoanis, nómadas y uno que otro personaje de ficción - narrativa o literaria - que permiten abarcar ampliamente el espectro de las formaciones que confluyen en el locus «isla Tierra».

En primer lugar surge la pregunta por la lógica de la representación espacial, por los mecanismos que tradicionalmente nos habían permitido hacernos una idea clara del espacio, que, según el autor, dejó de ser motivo del discurso filosófico desde el siglo XVII. Triste pérdida que da lugar a partir de entonces a amplias disertaciones sobre el no menos interesante, pero subordinado, tema del tiempo. Para devolver su lugar al espacio en el discurso filosófico - o quizá para dar espacio al discurso filosófico - Salvador Gallardo Cabrera nos guía a través de las islas, esos lugares que se sustraen del cálculo y la lógica del espacio y de las que, hoy día, la Tierra forma parte. Como habitantes de una isla, «robinsones» en palabras del autor, es menester que estudiemos la manera en la que concebimos el lugar que nos alberga, sin dejarnos llevar por los espejismos que la representación lógica del espacio ha impuesto sobre nuestra mente y que amputa nuestra percepción, puesto que «son las necesidades de los robinsones las que interpretan el mundo» (p. 31). Nuestras necesidades han cambiado, y nosotros, robinsones contemporáneos, habitamos un mundo inconmensurable. Si bien hubo un día en que el discurso geométrico de la modernidad dejó de lado a la filosofía en lo que a cuestiones de espacio se refería, es ahora esta lógica moderna de los espacios la que caduca, pues sus cálculos y medidas no pueden dar cuenta ya de las potencialidades del espacio. Parece entonces pertinente recurrir de nuevo a un discurso diferente al de la ciencia, que podría ser el de la filosofía si esta es capaz de tomar el ejemplo de otras ramas del saber que, a diferencia de ella, nunca abandonaron su preocupación por el espacio y siguieron abordando el tema desde las perspectivas más insólitas y variadas. La necesidad se impone: «Es el fin de la representación como lógica de los cuerpos. Los espacios se abren» (p. 69).

Nos encontramos después con una cuestión fundamental, a saber, ¿qué es lo que hace del espacio un tema tan importante para la filosofía y que por lo tanto justifica la necesidad de abordarlo desde 
esta perspectiva? Bueno, el espacio es mucho más que lo mensurable, el espacio no es medida, es más que un plano donde se desplazan los cuerpos, o donde es posible verificar la «realidad» de éstos. Mucho más allá de eso, el espacio es el lugar - en el sentido más amplio-, es la posibilidad de aparición no sólo de los cuerpos, si no de la construcción de los modos de existencia. Los modos de existencia se configuran en relación con los espacios. Dos de ellos son estudiados por Gallardo Cabrera, y cada uno de ellos da como resultado una forma de subjetividad en particular: los desiertos de arena y los desiertos de hielo.

Los primeros, desiertos de arena, han sido el espacio de construcción por excelencia de las subjetividades; los griegos, estoicos, cristianos, los prehispánicos, son algunos de los modos de existencia que toman forma en las arenas del desierto. En los fríos del desierto de hielo surgen - esporádicamente, como los copos de nieve - formas de vida como los inuit y otras figuras que vagan por la arena helada, haciendo del no-lugar su lugar sin límite. Los desiertos son para el autor un espacio donde se vuelve posible el surgimiento de subjetividades, modos de ser, formas de vida y existencia. El desierto es el sitio al que uno recurre cuando quiere dar forma a su ser; sin embargo, no hay que perder de vista que, como bien se señala en el texto, la finalidad de recurrir al desierto no es la de quedarse encerrado en él: «La posibilidad de nuevos procesos de subjetivación, de un nuevo arte de vivir, se juega en la exterioridad de las formas y en el afuera surcado por las fuerzas, no en el despertar de una bella interioridad. No es, en primera instancia, una cuestión ética sino de formación de espacios» (p. 72). Construirse a sí mismo es abrir nuevos espacios de posibilidad, a partir de un espacio vasto y abierto, no estéril.

Por último, al adentrarse en las aguas del mar, el libro nos invita a cuestionarnos por las formas de representación que han dado forma a los símbolos que conforman estructuras tan importantes como el Estado. En esta última parte de la exploración de los espacios, se estudia una analogía muy recurrida que equipara al Estado - y a uno mismo - con una embarcación que debe navegar a través de aguas siempre cambiantes y enfrentarse con monstruos que amenazan su estabilidad y permanencia en la superficie de las 
aguas. ¿Qué es lo que representa para nosotros el mar?, ¿qué representan las costas, los mapas, la embarcaciones? Estas inquietudes dieron forma alguna vez al pensamiento de la política, «antes del que el asfalto se convirtiera en el territorio político por excelencia» (p. 127). Por este mar navegan distintas embarcaciones: naves de cartógrafos, que intentan poner al espacio un orden; la Stultifera Navis que no tiene destino ni puerto; o los barcos de los exploradores, que hacen de esta res incognita su morada y punto de referencia. Gallardo Cabrera saca a la superficie símbolos olvidados, que han ido moldeando nuestras formas de representación, representación rota, que en la actualidad no gurda relación alguna con su referente.

Este es pues un libro sobre el espacio atravesado por mares, vientos, formas de vida, desiertos, costas y por el mismo tiempo. Es él mismo un espacio en el que confluyen cuestionamientos fundamentales a nuestra noción de realidad, libertad, verdad, razón y orden. El texto invita - si no es que obliga - a abandonar la estructura mental con la que nos enfrentamos al mundo para dejar que de éste surja otro logos, uno que atienda al espacio, con sus muy extensas posibilidades.

Cerrar el libro es como salir de una isla, desplegada en un lugar ignoto de un mar sin medidas.

María Isabel Cabrera Manuel

Departamento de Filosofía Universidad Autónoma de Aguascalientes 